\title{
$\angle S$ Research Square \\ The Tissue Expression of MCT3, MCT8, and MCT9 Genes in Women with Breast Cancer
}

\section{Ehsan Sohrabi}

Iran University of Medical Sciences

Masoumeh Moslemi

Iran University of Medical Sciences

\section{Ehsan Rezaie}

Baqiyatallah University of Medical Sciences

\section{Nahid Nafissi}

iran university of medical sciences

\section{Hamed Afkhami}

Shahed University Faculty of Medical Sciences

Mansoor Khaledi

Shahed University Faculty of Medical Sciences

Javad Fathi

Shiraz Medical School: Shiraz University of Medical Sciences

\section{Ali Zekri ( $\square$ h.a.university.ac@gmail.com )}

Iran University of Medical Sciences

\section{Research article}

Keywords: Cancer metabolism, Monocarboxylate transporters, Lactate dehydrogenase, Breast cancer

Posted Date: November 13th, 2020

DOI: https://doi.org/10.21203/rs.3.rs-104529/v1

License: (1) (i) This work is licensed under a Creative Commons Attribution 4.0 International License. Read Full License

Version of Record: A version of this preprint was published at Genes \& Genomics on June 7th, 2021. See the published version at https://doi.org/10.1007/s13258-021-01116-w. 


\section{Abstract}

Background: Breast cancer (BC) is a common malignancy with a high mortality rate. Malignant cell transformation is associated with metabolic changes. One group pf proteins that are affected are the monocarboxylate transporters (MCTs-SLC16A). The MCTs comprise 14 members, and they play an important role in the growth, proliferation, and metabolism of cancer cells by transporting monocarboxylates such as lactate, pyruvate and thyroid hormones. We aimed to evaluate the expression of MCT3 (SLC16A8), MCT8 (SLC16A2) and MCT9 (SLC16A9) genes in breast cancer samples, comparing to normal adjacent tissues.

Methods: Forty paired breast cancer tumor samples, the adjacent non-tumor and five healthy tissues were collected. Three cancer cell lines (MCF-7, MDA-MB-231, and SKBR3) were also analysed. The expression of SLC16A8, SLC16A2 and SLC16A9 were assessed using quantitative real-time PCR (qRT-PCR). The relationship between gene expression with the pathological features of the tumors, and the hormone receptors status [estrogen receptor (ER), progesterone receptor (PR) and human epidermal growth factor receptor 2 (HER2)] of the patients tumors were also analyzed. Microarray data and survival analyses for each of the candidate genes was undertaken

Results: There was a significantly lower expression of the MCT3 gene in tumor samples compared to adjacent normal tissue and healthy samples (P-value $<0.05)$. There was a significant difference in the expression of all three candidate genes between the BC tissues and normal tissues, and for the, tissues with different hormone receptor status (ER, PR and HER2) and the molecular subtypes. Altered MCT8 and MCT9 gene expression was associated with a reduced survival

Conclusion: MCT3 expression is significantly downregulated in breast cancer tissue. MCT3 may represent a novel therapeutic target in breast cancer patients, or in some hormone receptor subgroups, such as HER2-negative or triple-negative.

\section{Introduction}

Breast cancer (BC) is the second most common global cause of cancer-related mortality after lung cancer $(1,2)$. The mortality remains high because of the lack of effective treatments (2-5). According to the molecular classification and microarray analysis of the patient's tumors, breast cancer may be categorized into five subgroups $(6,7)$ : Luminal A [estrogen receptor (ER) positive, progesterone receptor (8) positive, and human epidermal growth factor receptor 2 (HER2) negative], Luminal B [ER, $\mathrm{PR}^{+}$, and HER2 $\left.{ }^{\text {low }}\right]$. HER2 over-expression (HER2 ${ }^{\text {high }}$, $E R^{\text {low }}$, and $P R^{\text {low }}$ ). Basal-like usually is Triple-negative (ER囚, $\mathrm{PR} \otimes$, and HER2 $₫$ basal marker) with the shortest survival. Normal breast tissue is $\mathrm{ER}^{\text {low }}, \mathrm{PR}^{\text {low }}$, and $\mathrm{P} 53^{+}$ $(6,7)$.

Several factors have been reported to be risk factors for the development of some cancers, including: metabolic disorders of glucose and lactate, hormonal disorders, smoking, physical inactivity, exposure to radiation, obesity, dietary factors, alcohol, age and mutagenic substances (9)., In cancer cells there is 
increased glycolysis leading to increased tissue levels of lactate, in both the absence of oxygen (anaerobic glycolysis) and in its presence (aerobic glycolysis or the Warburg effect) and this is associated with tumor progression (10). Increased glycolysis leads to an increased production of lactate and acidification of the tumor microenvironment (11), but whilst there is a reduction in extracellular $\mathrm{pH}$, the intracellular $\mathrm{pH}$ is often normal or even in some conditions may be alkaline; this is due to expression and function of a group of membrane-proteins that called the monocarboxylate transporters (MCTsSLC16A) and lactate dehydrogenases (LDHs) $(10,12-14)$. The MCTs family of proteins comprises 14 members, which mainly function as transporter proteins and transport monocarboxylates (lactate, pyruvate, and ketones), thyroid hormones, and carnitine $(8,15,16)$.

An increased tissue expression of some MCTs has been demonstrated in breast cancer compared to normal breast tissue: for example, MCT1 is reported to be up-regulated in the basal (17), luminal-like subtypes of breast cancer and the MCF7 cell line and also MCT4 is up-regulated in MDA-MB-231 cell line (18). MCT1 knockdown was found to reduce metastasis and angiogenesis of cancer cells (19-21). MCT1 and MCT4, two members of this family, have been extensively studied in various cancers and have been proposed as therapeutic targets for cancer, but the activity and expression of other MCTs in breast cancer have not been extensively studied $(14,16,22)$. These studies indicate the importance of this genes in cancer cell proliferation, metastasis, and since the expression of 3 members of this family MCT3, MCT8 and MCT9 have not been examined in breast cancer, we focused on these in this current study.

MCT3 protein is involved in the transport of ketones, pyruvate, and lactate and is expressed in most tissues. The gene for MCT3 (SCL16A8) is located on the long arm of chromosome 17 (23). The MCT8 protein was discovered in 1994 and is encoded by a gene (SLC16A2) on the long arm of the $X$ chromosome (15). It binds to thyroid hormone in mice and humans and whilst homologous to MCT10 (24), does not play a role in the transport of lactate, aromatic amino acids and sulfonated iodothyronines (16). Decreased expression level of MCT8 in thyroid cancer has been suggested MCT8 as a marker of thyroid differentiation. It is also expressed in the brain, heart, kidney, liver, and testis (25). Mutation in this gene result in the Allan-Herndon-Dudley syndrome (AHD)(26). The MCT9 protein plays a role in the transport of substances such as carnitine and is expressed in most tissues $(15,23)$. It is encoded by a gene (SCL16A9) located on the long arm of chromosome $10(8,15)$.

In this study, we evaluated the mRNA expression of these genes in breast cancer samples using the realtime PCR technique.

\section{Methods}

\section{Study population}

Breast tumor tissues $(n=40)$, normal adjacent tissues $(n=40)$ and 5 healthy breast tissue samples were collected from the 2018 to 2020 from the Rasoul Akram Hospital, Tehran, Iran. All patients were identified to have breast cancer, based on the Laboratory and histological criteria, and have given informed written 
consent before surgery. The study was approved by the Ethics Committee of Iran University of Medical Sciences, Tehran, Iran with code number IR.IUMS.FMD.REC.1397.159. According to the patient's history, none of the patients had received chemotherapy or radiotherapy and had no other malignancies. Healthy breast tissues obtained from normal individuals without any history of the disease. Pathological and clinical data including breast tumor ER, PR, and HER2 status by Laboratory tests (like IHC) were obtained for each patient.

\section{Cell Lines and Cell Culture}

The following human BC cell lines were purchased from the Pasture (Iran, Tehran) MCF-7 (ER + Luminal A-like BC cell model), MDA-MB231 (Basal like BC cell model), and SKBR3 (Her2 positive BC cell model). Cells were cultured in RPMI 1640 medium (Invitrogen, Auckland, New Zealand) supplemented with 10\% heat-inactivated fetal bovine serum (Invitrogen), $2 \mathrm{mM} \mathrm{L-glutamine,} 100 \mathrm{U}$ per ml penicillin, $100 \mu \mathrm{g}$ per $\mathrm{ml}$ streptomycin (Gibco BRL, Rockville, MD, USA), and $2 \mathrm{~g} / \mathrm{L}$ sodium bicarbonate (Sigma, St. Louis, MO). The cells were incubated at $37^{\circ} \mathrm{C}$ in a humidified atmosphere with $5 \% \mathrm{CO} 2$.

\section{RNA extraction and cDNA synthesis}

$1.5 \mathrm{ml}$ of cell culture medium and some (about 2 to $4 \mathrm{mg}$ ) of tissues stored at $-80 \mathrm{C}$ were used for RNA extraction. Total RNA was extracted from breast tissues and three cell line using RiboEX isolation reagent (GeneAll Biotech, Korea) according to the manufacturer's instructions. RNA was dissolved in DEPC-treated water and its concentration was determined with a NanoDrop one $\mathrm{C}$ spectrophotometer (Thermo Fisher Scientific, US). $1 \mu \mathrm{g}$ total RNA from each sample was used for CDNA synthesis with the TAKARA kit (Primer Script ${ }^{\text {TM }}$ RT reagent Kit, Japan) based on the manufacturer's protocol.

\section{Quantitative Real-Time Polymerase Chain Reaction}

Quantitative real-time PCR (qRT-PCR) was performed on ABI StepOne Sequence Detection System (Applied Biosystems, USA) using a SYBR Green-based PCR kit (Ampliqon, Denmark). The reaction was performed using a single cycle in $95^{\circ} \mathrm{C}$ for 15 min followed by continual 45 cycles ( $95^{\circ} \mathrm{C}$ for 10 seconds, $60^{\circ} \mathrm{C}$ for 20 seconds and $72 \mathrm{C}$ for 30 seconds). The primer sequences for each gene are listed in Table 1. Each reaction was followed by melting curve analysis Involving heating of the PCR product from 60 to $95^{\circ} \mathrm{C}$. The melt curve in the samples was compared with melt curve of positive and negative control to recognize specific amplicon from primer dimer formation. 
Table 1

Primer sequences were designed using Primer3.0 plus online tool used for real-time quantitative PCR

\begin{tabular}{|llll|}
\hline Primer & Forward sequence & Reverse sequence & Product size \\
\hline HPRT & CTGGCGTCGTGATTAGTGATG & AGACGTTCAGTCCTGTCCATAA & 130 \\
MCT3 & AGCCGTGAGCGTCTTCTTC & GTCAGGTAGAGCTCCAGGAG & 231 \\
MCT8 & CATCTGGGCCTTCGGAATTG & CTGACACAAGACGCCCAAG & 158 \\
MCT9 & TGTTCTTTGCTGGACTTGGA & CCAGCAGCAGAATAAAACCTC & 135 \\
\hline
\end{tabular}

Hypoxanthine phosphoribosyltransferase1 (HPRT1) was amplified as internal control that showed the least variation in gene expression between our normal and tumor samples.

\section{MRNA microarray profiling data analysis}

The UALCAN (http://ualcan.path.uab.edu/index.html), an interactive web resource (27) was used to explore the mRNA expression levels of the candidate genes in tumor and normal breast tissues data.

Breast Cancer Gene-Expression Miner v4.4 (bc-GenExMiner v4.4) (http://bcgenex.centregauducheau.fr), is a statistical mining tool of published annotated breast cancer transcriptomic data (DNA microarrays [ $\mathrm{n}=$ 10001]) $(28,29)$. It offers the possibility to explore gene-expression of genes of interest in breast cancer. Targeted expression analysis performed with DNA microarrays data and different population such as Receptor statuses (ER, PR and HER2 by IHC), Age and molecular subtype.

\section{Survival analysis}

To further validate, we used the Kaplan-Meier plotter database, which includes gene chip and RNA-seq data - sources for the databases include GEO, EGA and TCGA. The primary purpose of these tools are a meta-analysis based discovery and validation of survival biomarkers (30). Kaplan-Meier plotter database is pan-cancer tools to analyze the relationship between gene expression of candidate genes and overall survival of $3955 \mathrm{BC}$ patients. Hazard ratio (HR), 95\% confidence intervals (Cl) and log-rank P-values were calculated.

\section{Statistical analysis}

All statistical analyses were performed using SPSS v.25 software (SPSS Inc., Chicago, IL, USA), Rest 2009 software (version 2.0.13) and GraphPad Prism v.7.0 (GraphPad Prism version 5.0, San Diego, USA). Rest is software for determining the relative expression results of real-time PCR that uses pair-wise fixed reallocation randomisation tests to analyse data (31). Descriptive statistical analysis was used to evaluate the expression of genes in the samples. P-values $<0.05$ were considered to be statistically significant.

\section{Results}




\section{Clinic-pathological assessment}

The mean age of patients at the time of diagnosis was $51.93 \pm 2.23$ (range between 30 and 73 years). According to TNM classifications, the tumors were staged by a pathologist, who had no prior knowledge of the test results. Clinicopathological factors including: age, tumor size, histological type, lymph node metastasis and TNM staging, were analyzed for evaluation of a correlation with considered genes expression (Table 2). The subtypes were classified as follows according to ER, PR, and HER2: Triplepositive (ER positive, PR positive, HER2 positive); HER2positive (ER negative, PR negative, and HER2 positive); HER2negative (ER positive, PR positive, and HER2 negative); and Triplenegative (ER negative, PR negative, and HER2 negative) subtypes. Most samples were of the Invasive ductal carcinoma type (93.4\%). $80 \%$ of patients were involved in pathologic stage I and II (32 of 40 ) and $70 \%$ of samples were invasive ductal carcinoma. Immunohistochemical subtypes of the 40 samples were categorized in four groups' inculing: Triplepositive (17\%); HER2positive (14\%); HER2negative (37\%) and Triplenegative (32\%). 
Table 2

Patient clinical and tumor data .

\begin{tabular}{|c|c|c|}
\hline Variable & Clinicopathologic parameter & (\%) percent of samples \\
\hline \multirow[t]{3}{*}{ Histological type } & NOS & 70 \\
\hline & NOS + comedo & 13 \\
\hline & Others & 17 \\
\hline \multirow[t]{3}{*}{ Tumor stage } & 1 & 20 \\
\hline & 2 & 60 \\
\hline & 3 & 16.7 \\
\hline \multirow[t]{3}{*}{ TNM } & $\mathrm{T} 1$ & 23.3 \\
\hline & $\mathrm{T} 2$ & 63.3 \\
\hline & T3 & 10 \\
\hline \multirow[t]{3}{*}{ Tumor type } & Invasive ductal carcinoma & 56.7 \\
\hline & Invasive ductal carcinoma + DCIS & 36.7 \\
\hline & Other type & 6.6 \\
\hline \multirow[t]{2}{*}{ Family history } & Yes & 26.7 \\
\hline & No & 73.3 \\
\hline \multirow[t]{2}{*}{ ER(Estrogen Receptor) } & NEG & 40.0 \\
\hline & POS & 60.0 \\
\hline \multirow[t]{2}{*}{ PR (Progesterone Receptor) } & NEG & 50 \\
\hline & POS & 50 \\
\hline \multirow[t]{2}{*}{ HER2 } & NEG & 76.7 \\
\hline & POS & 23.3 \\
\hline \multirow[t]{2}{*}{ Age } & Mean $=51$ & $\operatorname{Min}=30$ \\
\hline & & $\operatorname{Max}=73$ \\
\hline
\end{tabular}

Expression of MCT3, MCT8 and MCT9 genes in tissue samples and their relationship to tumor subtypes

According to the obtained data, there was a significant down regulation of the MCT3 gene in the tumor tissues compared to healthy $(P$-value $=0.0001)$ and adjacent $(P$-value $=0.004)$ tissues $($ Fig. 1$)$. Expression level of MCT3 gene in four common subgroups of breast cancer showed that triple negative compared with triple positive was not significant decreased in expression level, but in HER2 negative comparison 
with HER2 positive subtype and HER2 positive comparison with triple negative subtype, the expression level of MCT3 gene over expressed non-significantly (Fig. 2).

MCT8 gene showed a non-significant down regulation in tumor tissues compared to adjacent and healthy tissues (Fig. 1). Expression level of this gene in subgroups of breast cancer showed that in HER2 negative comparison with HER2 positive subtype, the expression level of MCT8 was significantly lower (P-value = 0.001). We also showed that MCT8 was significantly overexpression in comparison between HER2 positive with the triple negative subtype (P-value $=0.027$ ). The expression level of MCT8 gene in the triple negative compared with triple positive tumor was not significantly lower in expression level (Fig. 2).

The MCT9 gene showed a non-significant down regulation in tumor tissues compared to adjacent and healthy tissues (Fig. 1), in subgroups of breast cancer the triple positive compared with triple negative tissue was not significant reduced in expression level, but in the HER2 negative comparison with the HER2 positive subtype and HER2 positive comparison with triple negative subtype, the expression level of MCT9 gene was over expressed non-significantly (Fig. 2).

Expression level of MCT3, МСТ8 and МСТ9 genes in tumors in relation to the clinical stage and grade.

In order to evaluate the expression of MCTs genes in different stages and grades of breast cancer, in compare to healthy tissue and each other, the samples were divided into 6 groups (stage I-III and grade IIII). The MCTs genes have down regulation in most stages compared to healthy tissue and down regulation of $M C T 3$ genes in stage I $(P$-value $=0.009)$, stage II $(P$-value $=0.0001)$ and stage III $(P$-value $=$ 0.013 ) has been significantly (Fig. 3). Also, the MCT8 gene showed a non-significant over expression in stage I compared to healthy tissue. Compared in the different stages, МСТ3 and МСT8 in stage II compared to stage I had a significant over expression (Table 3).

Table 3

Differences in the expression (expression ratio) of monocarboxylate transporters (MCTs) in tumors in relation to the clinical stage.

\begin{tabular}{|lllllll|}
\hline Gene & Stage II vs Stage & P value & $\begin{array}{l}\text { Stage II vs Stage } \\
\text { III }\end{array}$ & $\begin{array}{l}\text { P } \\
\text { value }\end{array}$ & $\begin{array}{l}\text { Stage I vs Stage } \\
\text { III }\end{array}$ & $\begin{array}{l}\text { P } \\
\text { value }\end{array}$ \\
\hline МСТ3 & $0.15(-0.1$ to 0.4$)$ & $0.029 *$ & $0.87(-0.4$ to 2.2$)$ & 0.892 & $5.74(4.6$ to 6.8$)$ & 0.272 \\
МСТ8 & $\begin{array}{l}0.17(-0.03 \text { to } \\
0.4)\end{array}$ & $0.003 * *$ & $0.39(-0.01$ to 0.8$)$ & 0.194 & $2.27(1.8$ to 2.8$)$ & 0.542 \\
\hline МСТ9 & $1.77(-0.2$ to 3.8$)$ & 0.821 & $0.95(-0.8$ to 2.8$)$ & 0.983 & $0.53(-1.3$ to 2.3$)$ & 0.79 \\
\hline
\end{tabular}

Also, The MCTs genes have down regulation in all grades compared to healthy tissue and down regulation of MCT3 genes in grade I $(P=0.027)$, grade II $(P=0.0001)$ and grade III $(P=0.005)$ has been significantly (Fig. 4). Compared in the different grades, none of the genes showed significant expression (Table 4). 
Table 4

Difference in expression (expression ratio) of monocarboxylate transporters (MCTs) in tumors in relation to the clinical grade.

\begin{tabular}{|c|c|c|c|c|c|c|}
\hline Gene & Grade II vs Grade & $\begin{array}{l}P \\
\text { value }\end{array}$ & Grade II vs Grade & $\begin{array}{l}P \\
\text { value }\end{array}$ & $\begin{array}{l}\text { Grade I vs Grade } \\
\text { III }\end{array}$ & $\begin{array}{l}\mathrm{P} \\
\text { value }\end{array}$ \\
\hline МСТ3 & 1.445 & 0.73 & 1.057 & 0.946 & 0.732 & 0.875 \\
\hline МСТ8 & 3.62 & 0.247 & 3.103 & 0.095 & 0.857 & 0.743 \\
\hline МСТ9 & 2.716 & 0.754 & 9.188 & 0.208 & 3.383 & 0.724 \\
\hline
\end{tabular}

\section{Expression level of MCT3, MCT8 and MCT9 genes in three cell lines}

MCF7 is representative of primary breast cancer cells (Invasive Ductal Carcinoma (IDC) OR luminalA) that express E-cadherin, ER and PR receptors $(32,33)$. MDA-MB-231 is representative of metastatic, aggressive and invasive adenocarcinoma cells, that are Vimentin- positive and dose not express E-cadherin, ER, PR and HER2 receptors (TNBC) (34). SKBR3 is representative of adenocarcinoma that over-expresses the HER2 gene product (HER2 positive) (35). All the genes in the three cell lines had non-significant decrease in expression compared to healthy tissues, Also our results showed that MCT-9 in MDA-MB-231 (P-value $=0.0001)$ and SKBR3 (P-value $=0.0001)$ cell lines down regulated compared to MCF-7 cell line, but MCT-3 in SKBR3 cell line $(P$-value $=0.0001)$ and MCT-8 in both SKBR3 $(P$-value $=0.0001)$ and MDA-MB-231 cell lines $(P$-value $=0.0001)$, up regulated compared to MCF-7 cell line (Fig. 5).

\section{Breast cancer microarray profiling data analysis}

The UALCAN analysis showed that while the expression level candidate genes decreased in BC primary tumors compared with normal cases (P-value < 0.001) (Fig. 6). The downregulation of candidate genes, have often been shown in a variety of cancers compared with normal cases (Fig. 7).

bc-GenExMiner analysis showed that MCT8 (SLC16A2) has significant difference in ER negative versus ER positive $(P$-value $=0.012)$ and HER2 negative versus HER2 positive $(P$-value $<0.0001)$ status. MCT3 (SLC16A8) has significant difference in ER negative versus ER positive (P-value < 0.0001), PR negative versus PR positive $(P$-value $=0.002)$ and HER2 negative versus HER2 positive $(P$-value $=0.004)$ status. MCT9 (SLC16A9) has significant difference in ER negative versus ER positive ( $P$-value $<0.0001)$, PR negative versus $P R$ positive $(P$-value $<0.0001)$ and HER2 negative versus HER2 positive $(P$-value $=0.002)$ status.

Also All three candidate genes have significant differences between age before and after 51 , and in each intrinsic molecular subtype with significantly P-value (Fig. 8-10).

The expression level of MCT8 and MCT9 were associated with poor overall survival in Breast cancer samples 
Using the Kaplan-Meier plotter database, we determined that the overall survival of 3955 BC patients (from the Kaplan-Meier plotter database) is low in cases with decreased expression of candidate genes. The follow-up time was determined in 250 months. The plots showed that low expression of SLC16A9 (MCT9) and SLC16A2 (MCT8) was associated with poor overall survival (Fig. 11).

\section{Discussion}

Nearly one in nine women develops breast cancer, and breast cancer accounts for about one-third of all cancers in women, the second most common cancer after lung cancer and the most common cause of cancer deaths among women (36). As a result, it is important to better understand and evaluate the genes and molecular markers involved in this cancer.

The important features of transporters in MCT superfamily are their ability to transport across membranes and their wide substrates, making them essential for many cellular processes and cancers (37). MCT3, MCT8 and MCT9 genes and their substrates not yet well understood and there is very limited information on the expression and their potential roles. That's why for the first time, we examined the expression of the MCT3, MCT8 and MCT9 genes in the patients with breast cancer and MCF7, SKBR3 and MDA-MB-231 cell lines.

Some members of the MCT family can be grouped together, for example MCT1 to MCT4 are involved in the transfer of monocarboxylates (like lactate and pyruvate) and also MCT8 and MCT10 are involved in the transfer of aromatic amino acids and thyroid hormones. But other components of this family are not included in a particular group due to the lack of complete substrate recognition (37). MCT1 and MCT4, are two members of this family that have been extensively studied in various cancers such as breast cancer and have been introduced as therapeutic targets for cancer, but the activity and expression of other members of this family in breast cancer have not been studied (37). MCT1 up-regulated in the basal (17), luminal-like subtypes of breast cancer and MCF7 cell line and targeted MCT1 can causes decrease in metastasis and angiogenesis of the cancer cells (19-21). Also, the MCT4 and MCT2 up-regulated in MDA-MB-231 and MCF-7 cell lines compared to HMEC 184 cells (18). In 2005, Zhu and et al demonstrated decreased expression of $\mathrm{MCT} 3$, and this was associated with increased severity of atherosclerosis (38). The MCT3 downregulation has also been observed in the non-small cell lung cancer (NSCLC) (39). Our results are also consistent with these results, showed a significant down regulation of this gene in tumor tissues compared to normal tissues, but MCT-3 in SKBR3 cell line over expressed compared to MCF-7 cell line. MCT3 gene expression in stage II disease was significantly different from stage I and stage III disease. These data suggest that in addition to being detectable in various breast cancer subtypes, these markers like HER2 $(40)$, and EphA2 $(41,42)$ may be used to predict the response to the treatment or disease progression.

MCT8 and MCT10 are expressed in heart, kidney, liver, skeletal muscle, placenta, testis and appears to perform a particularly useful function in the brain where it is necessary for the thyroid hormone uptake that is important for normal brain development (25). Badziong,et,al showed that the MCT8 expression 
was downregulated in both benign and the malignant thyroid tumors as compared to the normal thyroid tissue, In contrast, significant upregulation of MCT8, LAT2 and LAT4 genes were found in Graves' disease, So in that research they suggested MCT8 is a appropriate object for thyroid differentiation and MCT8 upregulation occurs in hyperfunctional thyroid tissue (25). Significant down regulation of MCT8 gene was also confirmed by Nwosu,et,al in 2017, with analysis eight microarray datasets in human hepatocellular carcinoma. In agreement with these studies, we found a significant reduction in the expression of this gene in the tumor tissues compared to the normal tissues. MCT8 is significantly overexpression in the comparison to HER2 positive with triple negative subtype; this means that HER2 expression is positively associated with increased expression of this gene. Also, in this study we reported upregulation of the MCT8 gene in the tumor tissue compared with the tumor adjacent tissues. This may indicate that the MCT8 gene could help differentiate tumor cells from adjacent cells and could be the possible mechanism for these associations.

So far, the MCT9 gene expression in various human cancers has not been studied by molecular methods such as real time PCR, but significantly down regulation in breast cancer has been identified using microarray analysis (43). The previous studies reported down regulation of the MCT9 gene in invasive breast cancer and also CNS diffuse large B-cell lymphoma compared to non-CNS diffuse large B-cell lymphoma by analyzing microarray data (44). MCT9 may be involved in aerobic glycolysis of malignant tumors and may be increased in certain types of lymphomas. MCT9 expression also significantly downregulated in MDA-MB-231 and SKBR3 cell lines compared to MCF-7 cell line.

\section{Conclusions}

Since the expression MCT3, MCT8 and MCT9 have not been examined in breast cancer previously this study may help to understand the importance of these genes in the breast cancer progression. The expression of MCT3 may be used as a prognostic marker; however, further research is required to confirm this.

\section{Limitations}

This study had some limitations, like that sample size. In other studies with larger sample size, it might be feasible to investigate a number of issues in detail, which needs a more homogenous clinical and molecular population. Also for validating these results, the complementary techniques such as western blotting could be explored.

In conclusion, MCT3 gene showed low expressions in tumor samples compared to adjacent normal and healthy mammary tissues. Besides, MCT3 can represent a novel therapeutic target in breast cancer patients or some of the following subgroups such as HER2-negative or triple-negative.

\section{Abbreviations}


$\mathrm{BC}$

Breast cancer, ER:Estrogen receptor, HER2:Human epidermal growth factor receptor 2, MCTs:Monocarboxylate transporters, LDHs:lactate dehydrogenases, AHD:Allan-Herndon-Dudley syndrome, HPRT1:Hypoxanthine phosphoribosyltransferase1.

\section{Declarations}

\section{Acknowledgment}

This study is financially supported by Iran University of Medical Sciences, Tehran, Iran, in 2018. All parts of the work were carried out in the 'Genetic laboratory of Ali Asghar Children's' and Rasoul Akram Hospitals, Tehran, Iran. The authors of the current study would like to express their deep thanks to all staff of these hospitals.

\section{Author Contributions}

E.S, N.N, A.Z and J.F are major contributors in writing the manuscript and design, M.M, E.H, H.A and M.KH participated in writing the manuscript, J.F, M.K, H.A and M.M participated in writing the manuscript and data interpretation, N.N,E.S and A.Z participated in design, participated in manuscript writing, and conducted statistics. All authors read and approved the final manuscript.

\section{Funding}

This study is financially supported by Iran University of Medical Sciences, Tehran, Iran.

\section{Availability of Data and Material}

The data that support the findings of this study are available.

\section{Ethics Approval and Consent to Participate}

The study was approved by the Ethics Committee of Iran University of Medical Sciences, Tehran, Iran with code number IR.IUMS.FMD.REC.1397.159.

\section{Consent for publication}

Not applicable.

\section{Competing interests}

The authors declare that they have no competing interests.

\section{Author details}


1. Department of Medical Genetics and Molecular Biology, Faculty of Medicine, Iran University of Medical Sciences (IUMS), Tehran, Iran.

2. Molecular Biology Research Center, Systems Biology and Poisonings Institute, Baqiyatallah University of Medical Science, Tehran, Iran

3. Breast Department of Rasool Hospital, Iran University of Medical Sciences (IUMS), Tehran, Iran

4. Department of Medical Microbiology, Faculty of Medicine, Shahed University of Medical Science, Tehran, Iran

5. Department of Bacteriology and Virology, School of Medicine, Shiraz University of Medical Sciences, Shiraz, Iran

\section{References}

1. Estiar MA, Esmaeili R, Zare A-A, Farahmand L, Fazilaty H, Zekri A, et al. High expression of CEACAM19, a new member of carcinoembryonic antigen gene family, in patients with breast cancer. Clinical experimental medicine. 2017;17(4):547-53.

2. Harding C, Pompei F, Burmistrov D, Welch HG, Abebe R, Wilson R. Breast cancer screening, incidence, and mortality across US counties. JAMA internal medicine. 2015;175(9):1483-9.

3. Si W, Li Y, Han Y, Zhang F, Wang Y, Li Y, et al. Epidemiological and clinicopathological trends of breast cancer in Chinese patients during 1993 to 2013: A retrospective study. Medicine. 2015;94(26).

4. Bogenrieder T, Herlyn M. Axis of evil: molecular mechanisms of cancer metastasis. Oncogene. 2003;22(42):6524.

5. Weigelt B, Peterse JL, Van't Veer LJ. Breast cancer metastasis: markers and models. Nature reviews cancer. 2005;5(8):591.

6. Liu Z, Zhang X-S, Zhang S. Breast tumor subgroups reveal diverse clinical prognostic power. Scientific reports. 2014;4:4002.

7. Yersal O, Barutca S. Biological subtypes of breast cancer: Prognostic and therapeutic implications. World J Clin Oncol. 2014;5(3):412.

8. Halestrap AP, Price NT. The proton-linked monocarboxylate transporter (MCT) family: structure, function and regulation. Biochem J. 1999;343(Pt 2):281.

9. Stein C, Colditz G. Modifiable risk factors for cancer. British journal of cancer. 2004;90(2):299-303.

10. Draoui N, Feron O. Lactate shuttles at a glance: from physiological paradigms to anti-cancer treatments. Dis Models Mech. 2011;4(6):727-32.

11. Aveseh M, Nikooie R, Aminaie M. Exercise-induced changes in tumour LDH-B and MCT1 expression are modulated by oestrogen-related receptor alpha in breast cancer-bearing BALB/c mice. J Physiol. 2015;593(12):2635-48.

12. Mishra D, Banerjee D. Lactate Dehydrogenases as Metabolic Links between Tumor and Stroma in the Tumor Microenvironment. Cancers. 2019;11(6):750. 
13. Pinheiro C, Longatto-Filho A, Scapulatempo C, Ferreira L, Martins S, Pellerin L, et al. Increased expression of monocarboxylate transporters 1, 2, and 4 in colorectal carcinomas. Virchows Arch. 2008;452(2):139-46.

14. Luz M, Perez M, Azzalis L, Sousa L, Adami F, Fonseca F, et al. Evaluation of MCT1, MCT4 and CD147 genes in peripheral blood cells of breast cancer patients and their potential use as diagnostic and prognostic markers. Int J Mol Sci. 2017;18(4):170.

15. Halestrap AP, Meredith D. The SLC16 gene family-from monocarboxylate transporters (MCTs) to aromatic amino acid transporters and beyond. Pflügers Archiv. 2004;447(5):619-28.

16. Van Der Deure WM, Peeters RP, Visser TJ. Molecular aspects of thyroid hormone transporters, including MCT8, MCT10, and OATPS, and the effects of genetic variation in these transporters. J Mol Endocrinol. 2010;44(1):1.

17. Pinheiro C, Albergaria A, Paredes J, Sousa B, Dufloth R, Vieira D, et al. Monocarboxylate transporter 1 is up-regulated in basal-like breast carcinoma. Histopathology. 2010;56(7):860-7.

18. Gallagher SM, Castorino JJ, Wang D, Philp NJ. Monocarboxylate transporter 4 regulates maturation and trafficking of CD147 to the plasma membrane in the metastatic breast cancer cell line MDA-MB231. Cancer research. 2007;67(9):4182-9.

19. Hussien R, Brooks GA. Mitochondrial and plasma membrane lactate transporter and lactate dehydrogenase isoform expression in breast cancer cell lines. Physiol Genom. 2010;43(5):255-64.

20. Sonveaux P, Végran F, Schroeder T, Wergin MC, Verrax J, Rabbani ZN, et al. Targeting lactate-fueled respiration selectively kills hypoxic tumor cells in mice. J Clin Investig. 2008;118(12):3930-42.

21. Végran F, Boidot R, Michiels C, Sonveaux P, Feron O. Lactate influx through the endothelial cell monocarboxylate transporter MCT1 supports an NF-KB/IL-8 pathway that drives tumor angiogenesis. Cancer research. 2011;71(7):2550-60.

22. Pinheiro C, Longatto-Filho A, Azevedo-Silva J, Casal M, Schmitt FC, Baltazar F. Role of monocarboxylate transporters in human cancers: state of the art. J Bioenerg Biomembr. 2012;44(1):127-39.

23. Pérez-Escuredo J, Van Hee VF, Sboarina M, Falces J, Payen VL, Pellerin L, et al. Monocarboxylate transporters in the brain and in cancer. Biochimica et Biophysica Acta (BBA)-Molecular Cell Research. 2016;1863(10):2481-97.

24. Friesema EC, Ganguly S, Abdalla A, Fox JEM, Halestrap AP, Visser TJ. Identification of monocarboxylate transporter 8 as a specific thyroid hormone transporter. J Biol Chem. 2003;278(41):40128-35.

25. Badziong J, Ting S, Synoracki S, Tiedje V, Brix K, Brabant G, et al. Differential regulation of monocarboxylate transporter 8 expression in thyroid cancer and hyperthyroidism. European journal of endocrinology. 2017;177(3):243-50.

26. Schwartz CE, Stevenson RE. The MCT8 thyroid hormone transporter and Allan-Herndon-Dudley syndrome. Best practice research Clinical endocrinology metabolism. 2007;21(2):307-21. 
27. Chandrashekar DS, Bashel B, Balasubramanya SAH, Creighton CJ, Ponce-Rodriguez I, Chakravarthi BV, et al. UALCAN: a portal for facilitating tumor subgroup gene expression and survival analyses. Neoplasia. 2017;19(8):649-58.

28. Jézéquel P, Frénel J-S, Campion L, Guérin-Charbonnel C, Gouraud W, Ricolleau G, et al. bc-GenExMiner 3.0: new mining module computes breast cancer gene expression correlation analyses. Database. 2013;2013.

29. Jézéquel P, Campone M, Gouraud W, Guérin-Charbonnel C, Leux C, Ricolleau G, et al. bc-GenExMiner: an easy-to-use online platform for gene prognostic analyses in breast cancer. Breast cancer research treatment. 2012;131(3):765-75.

30. Györffy B, Lanczky A, Eklund AC, Denkert C, Budczies J, Li Q, et al. An online survival analysis tool to rapidly assess the effect of 22,277 genes on breast cancer prognosis using microarray data of 1,809 patients. Breast cancer research treatment. 2010;123(3):725-31.

31. Pfaffl MW, Horgan GW, Dempfle L. Relative expression software tool (REST@) for group-wise comparison and statistical analysis of relative expression results in real-time PCR. Nucleic acids research. 2002;30(9):e36-e.

32. Zheng A, Kallio A, Harkonen P. Tamoxifen-induced rapid death of MCF-7 breast cancer cells is mediated via extracellularly signal-regulated kinase signaling and can be abrogated by estrogen. Endocrinology. 2007;148(6):2764-77.

33. Hiscox S, Baruah B, Smith C, Bellerby R, Goddard L, Jordan N, et al. Overexpression of CD44 accompanies acquired tamoxifen resistance in MCF7 cells and augments their sensitivity to the stromal factors, heregulin and hyaluronan. BMC Cancer. 2012;12(1):458.

34. Lacroix M, Haibe-Kains B, Hennuy B, Laes J-F, Lallemand F, Gonze I, et al. Gene regulation by phorbol 12-myristate 13-acetate in MCF-7 and MDA-MB-231, two breast cancer cell lines exhibiting highly different phenotypes. Oncol Rep. 2004;12(4):701-7.

35. Dai X, Cheng H, Bai Z, Li J. Breast cancer cell line classification and its relevance with breast tumor subtyping. J Cancer. 2017;8(16):3131.

36. Wolman I. Berek and Novak's gynecology 15th edition. Springer; 2014.

37. Halestrap AP. The SLC16 gene family-structure, role and regulation in health and disease. Mol Aspects Med. 2013;34(2-3):337-49.

38. Zhu S, Goldschmidt-Clermont PJ, Dong C. Inactivation of monocarboxylate transporter MCT3 by DNA methylation in atherosclerosis. Circulation. 2005;112(9):1353-61.

39. Eilertsen M, Andersen S, Al-Saad S, Kiselev Y, Donnem T, Stenvold H, et al. Monocarboxylate transporters 1-4 in NSCLC: MCT1 is an independent prognostic marker for survival. PloS one. 2014;9(9).

40. Wong DJ, Hurvitz SA. Recent advances in the development of anti-HER2 antibodies and antibodydrug conjugates. Annals of translational medicine. 2014;2(12).

41. Rezaie E, Amani J, Pour AB, Hosseini HM. A new scfv-based recombinant immunotoxin against EPHA2-overexpressing breast cancer cells; High in vitro anti-cancer potency. European Journal of 
Pharmacology. 2020:172912.

42. Rezaie E, Pour AB, Amani J, Hosseini HM. Bioinformatics Predictions, Expression, Purification and Structural Analysis of the PE38KDEL-scfv Immunotoxin Against EPHA2 Receptor. International Journal of Peptide Research and Therapeutics. 2019:1-18.

43. Kim GR, Ku YJ, Cho SG, Kim SJ, Min BS. Associations between gene expression profiles of invasive breast cancer and Breast Imaging Reporting and Data System MRI lexicon. Annals of surgical treatment research. 2017;93(1):18-26.

44. DO HYOUNG L, Kim WS, Kim SJ, Yoo HY, Ko YH. Microarray gene-expression profiling analysis comparing PCNSL and non-CNS diffuse large B-cell lymphoma. Anticancer research. 2015;35(6):3333-40.

\section{Figures}

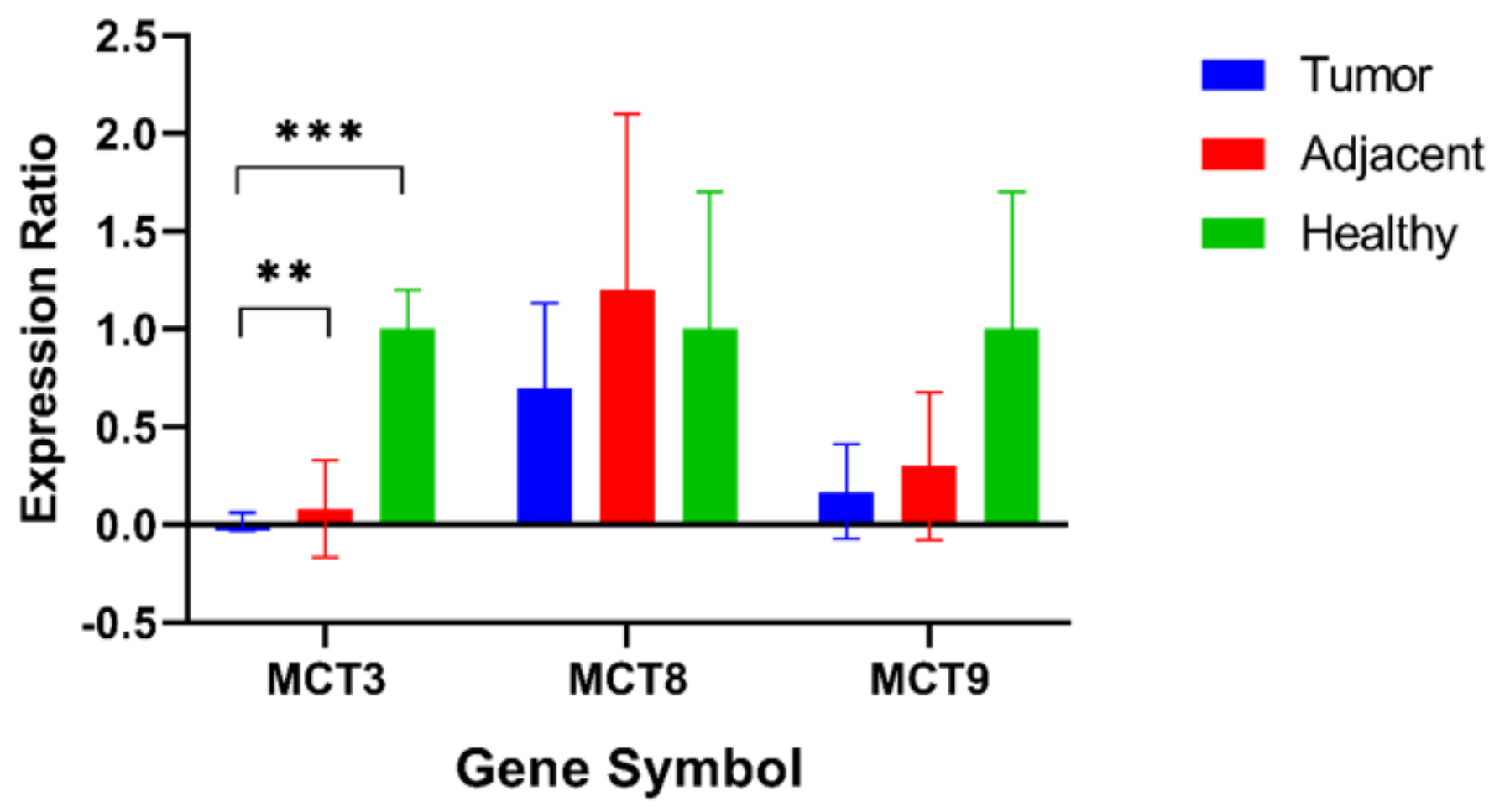

\section{Figure 1}

The relative gene expressions of MCT3, MCT8 and MCT9 in different tissues. MCT-3, MCT-8 and MCT-9 genes are down regulated in tumor and adjacent samples compared to healthy tissues. Data shown are mean $[ \pm S D]$ OD values. *Value shown $p$-value $<0.05, * *$ value shown $p$-value $<0.01$ and ${ }^{* \star *}$ value shown p-value $<0.001$. 


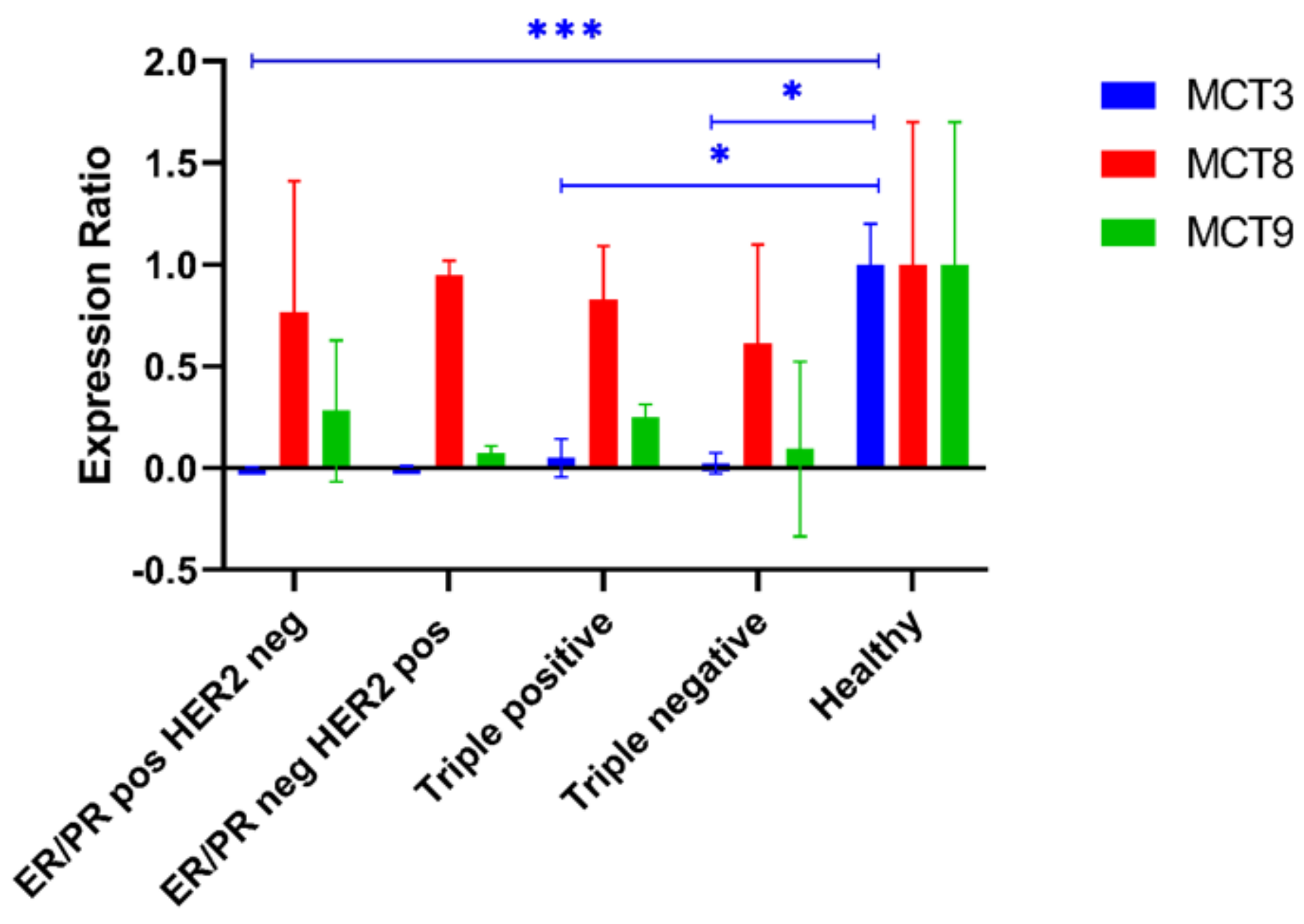

Compare Subtype

Figure 2

Expression of genes in subtype of breast cancer. Comparing breast cancer subtypes with healthy tissue, the MCT3 gene in three subtypes of negative triple $(P=0.03)$, positive triple $(P=0.031)$ and Her2 negative $(P=0.0001)$ had a significant down regulation. Data shown are mean $[ \pm S D]$ OD values. *Value shown $p-$ value $<0.05, \star \star$ value shown $p$-value $<0.01$ and $* \star \star v a l u e ~ s h o w n ~ p$-value $<0.001$ 


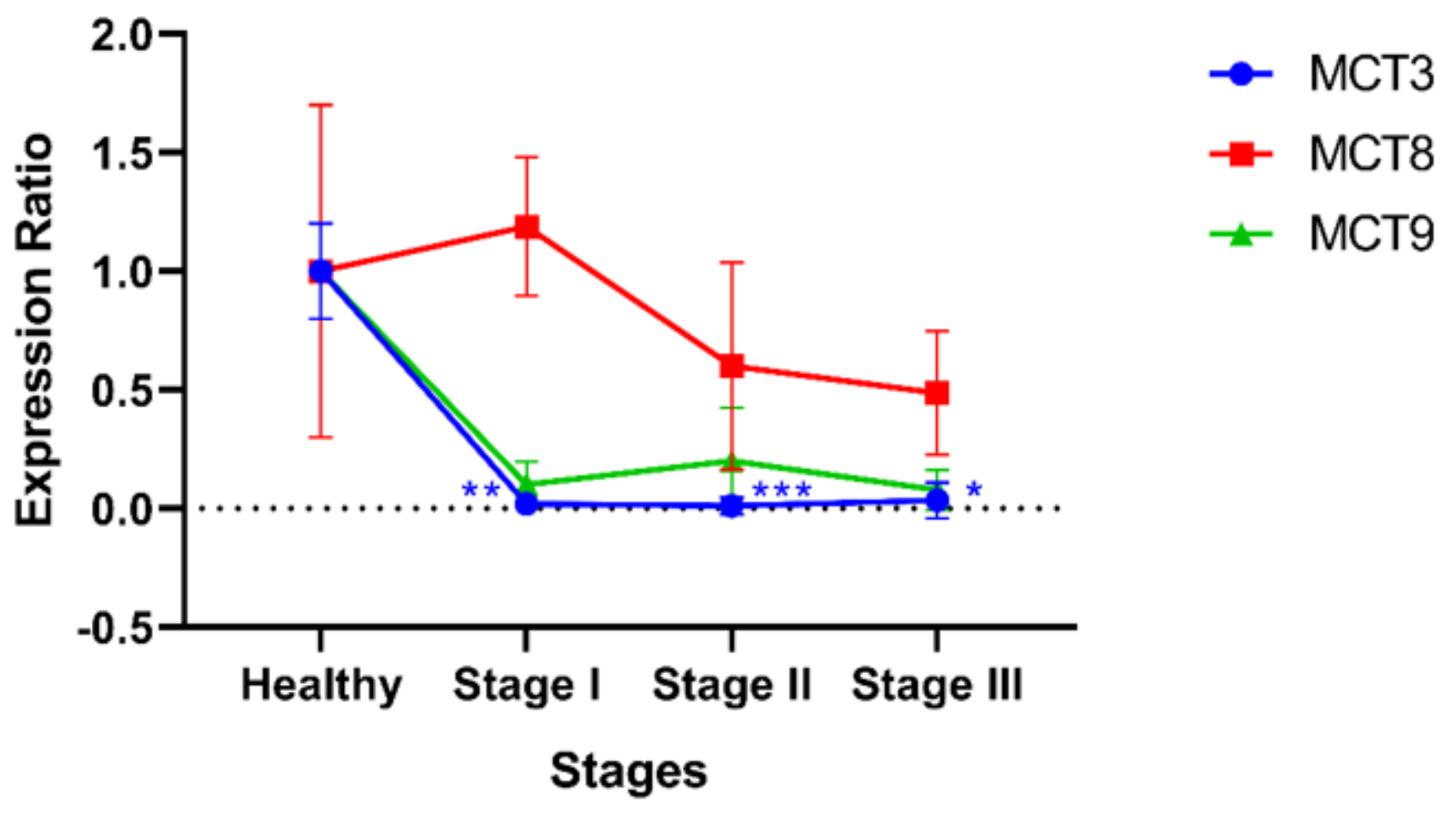

Figure 3

Expression of genes in different stages of breast cancer comparing with healthy tissue, the MCT3 gene in three stages had a significant down regulation. Data shown are mean $[ \pm S D]$ OD values. *Value shown $p$ value $<0.05,{ }^{\star *}$ value shown $\mathrm{p}$-value $<0.01$ and ${ }^{\star \star *}$ value shown $\mathrm{p}$-value $<0.001$

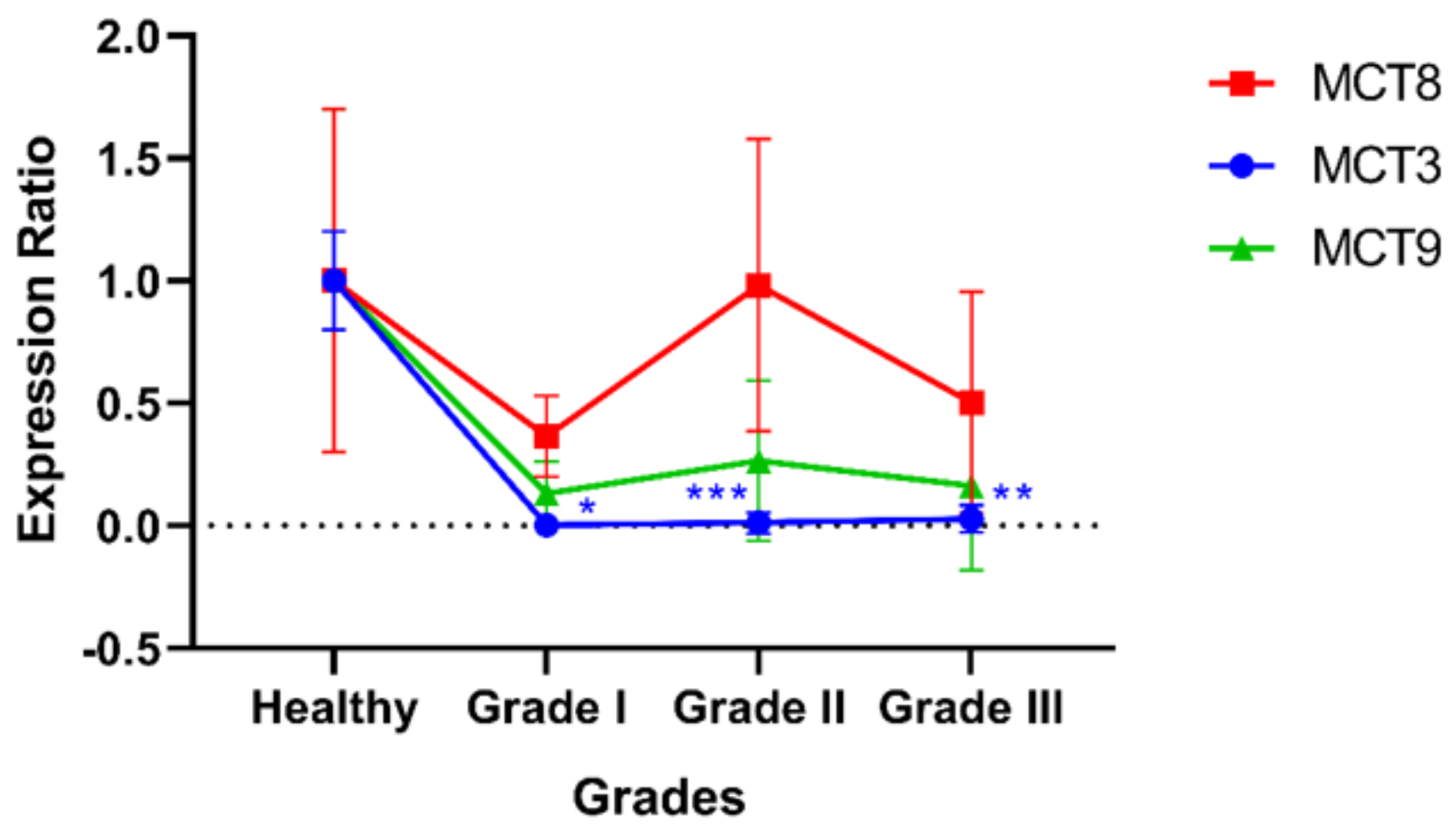


Figure 4

Expression of genes in different grades of breast cancer comparing with healthy tissue, the MCT3 gene in three grades had a significant down regulation. Data shown are mean $[ \pm S D]$ OD values. *Value shown $p-$ value $<0.05, * \star$ value shown $p$-value $<0.01$ and $\star \star \star$ value shown $p$-value $<0.001$

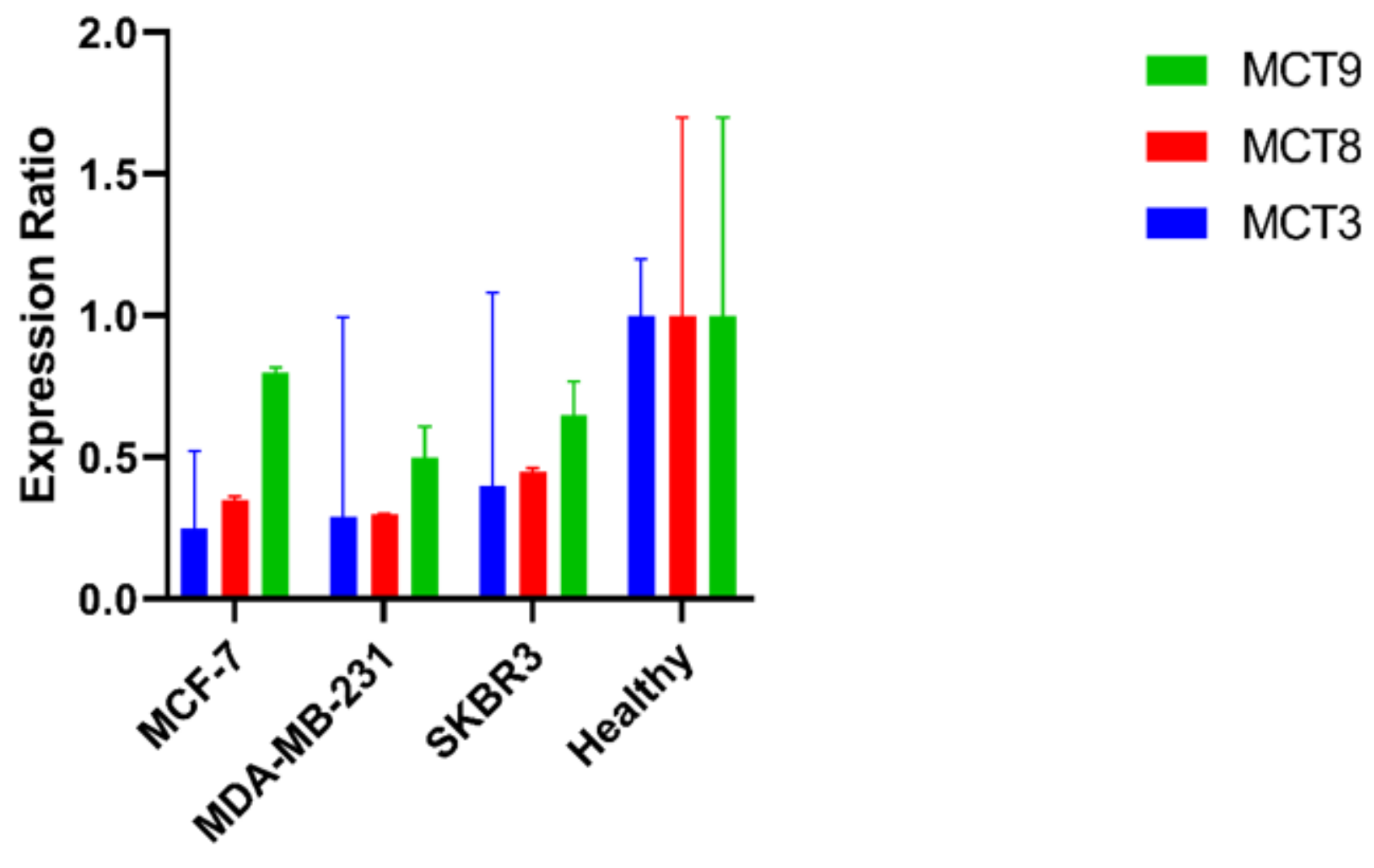

Compare Cell lines

Figure 5

The relative gene expressions of MCT3, MCT8 and MCT9 breast cancer cell lines compared to healthy tissues. Data shown are mean $[ \pm S D]$ OD values. 

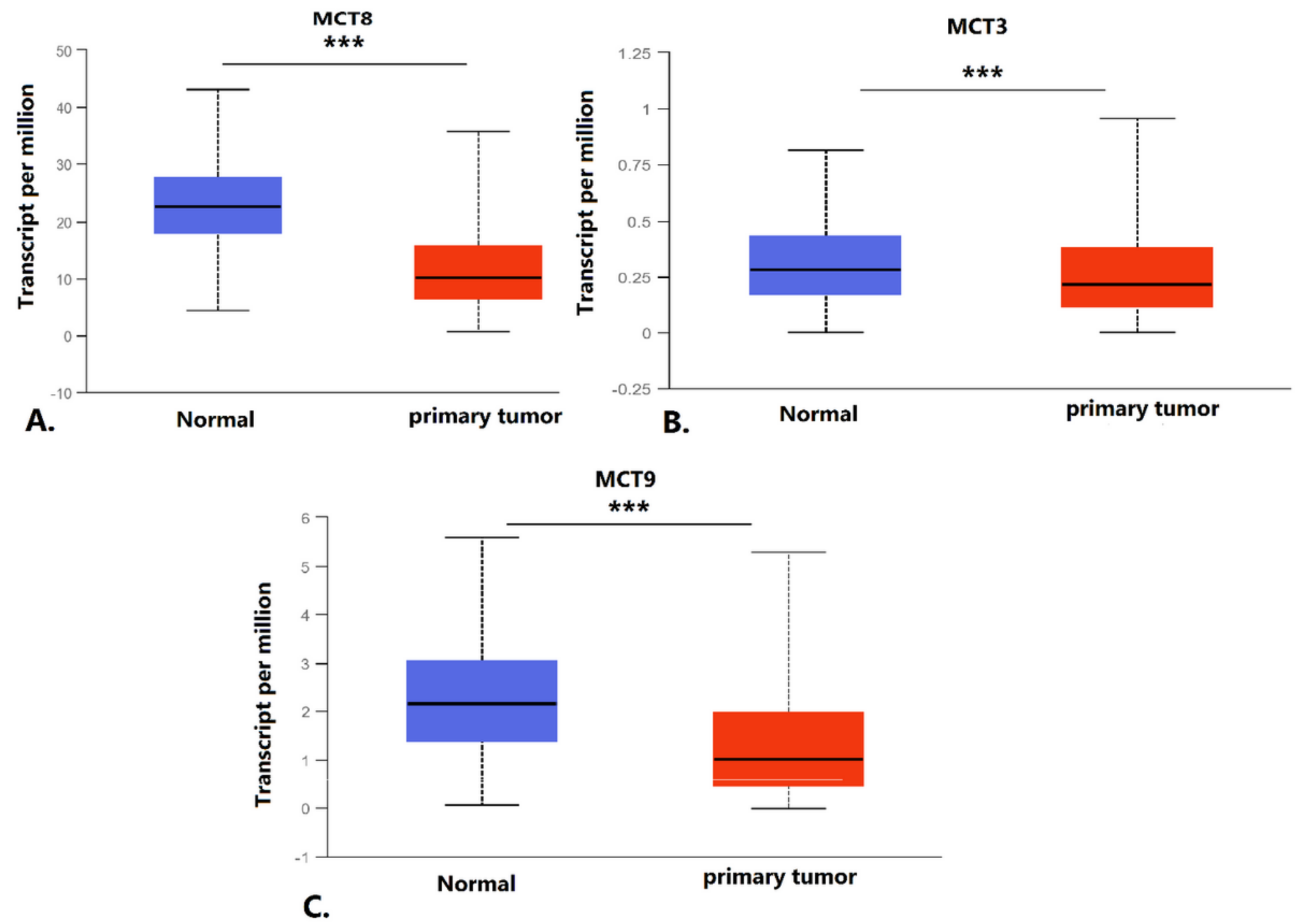

Figure 6

Expression validation in the UALCAN database for downregulated MCT8 (A), MCT3 (B) and MCT9 (C) genes in breast cancer samples. Blue box plot represent Normal samples $(n=114)$ and red box plot represent primary tumor samples $(n=1097)$. (Data from The Cancer Genome Atlas (TCGA) database) $(\star \star \star$ P-value $<0.001)$ 

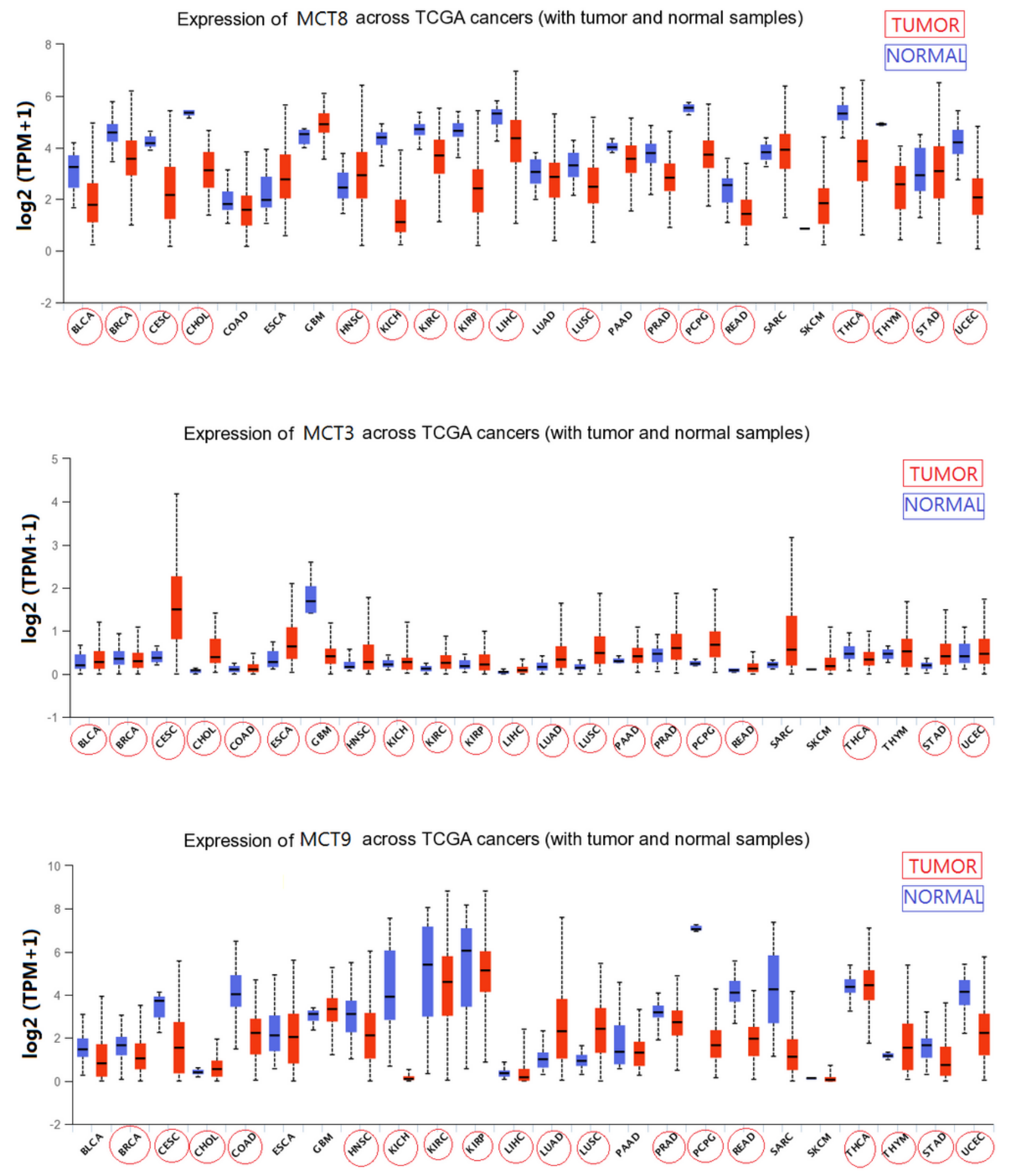

\section{Figure 7}

TCGA data analysis of the mRNA level of MCT8, MCT3 and MCT9 genes in different types of cancer. Cancer types with significantly decreased mRNA levels are highlighted with a red circle. 


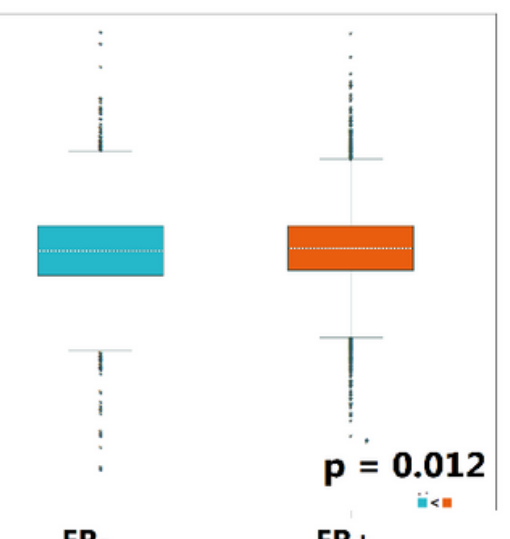

ER(2362)

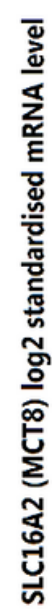

A.
B.

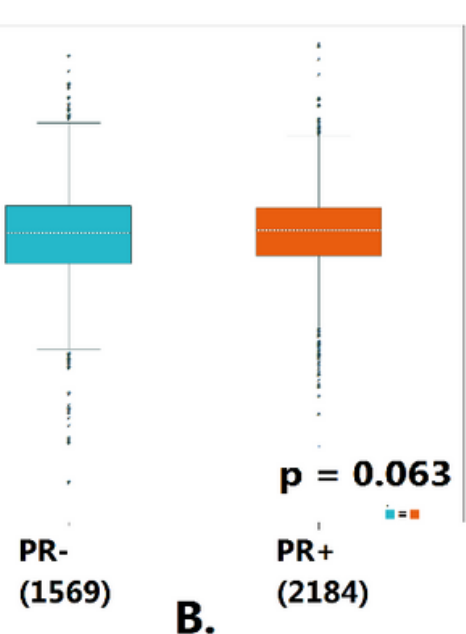

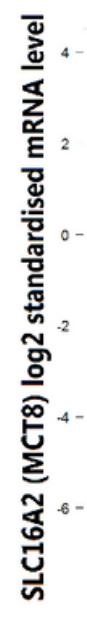

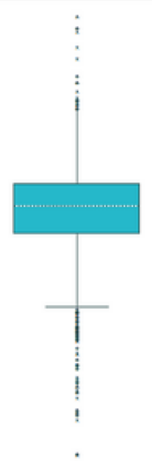

HER2$\mathrm{p}<0.0001$

(2387)

c.
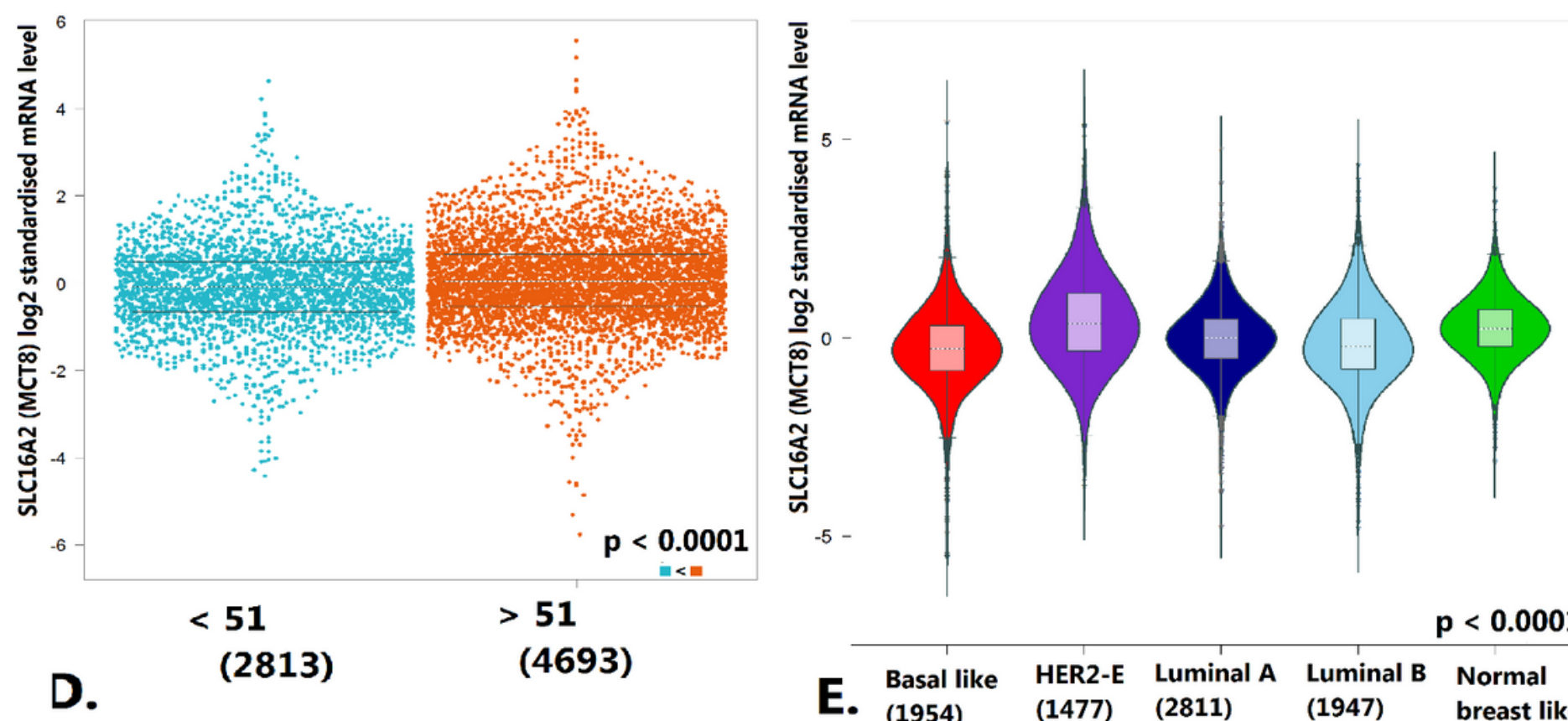

E. Basal lik

HER2-E Luminal A

(1477) (2811) HER2 +

(436) 


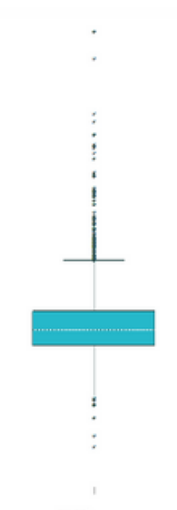

ER(2289)
">"

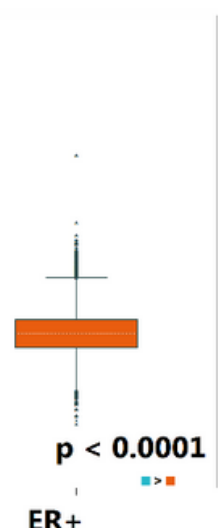

(6376)

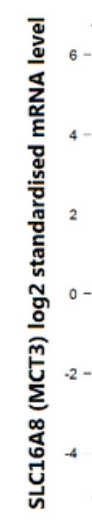

西

A.

$$
\text { . }
$$

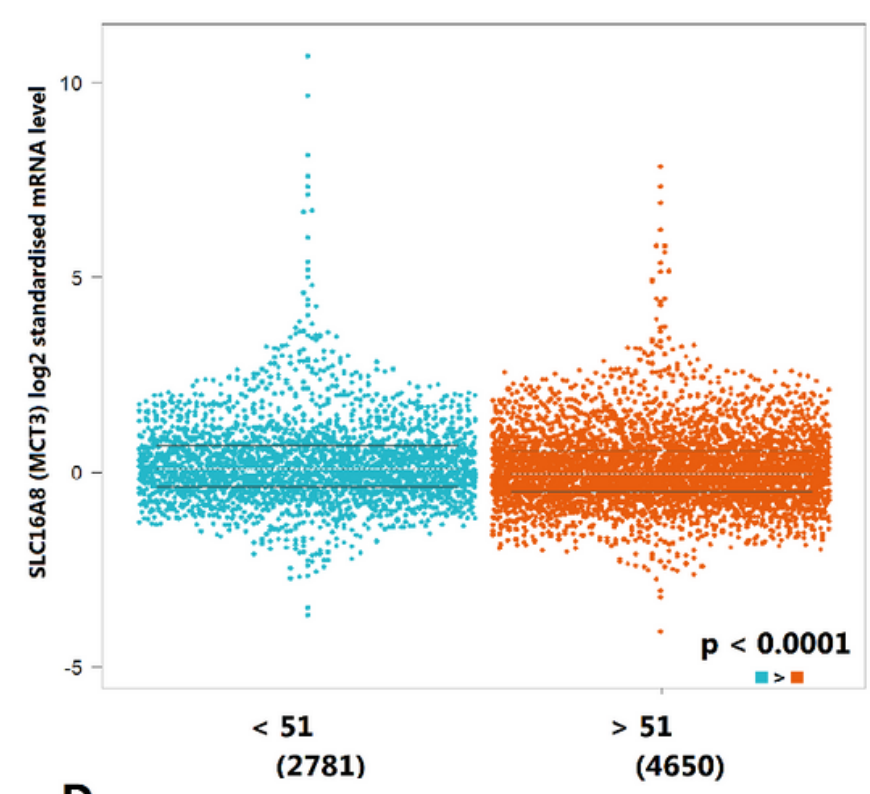

D.

(4650)
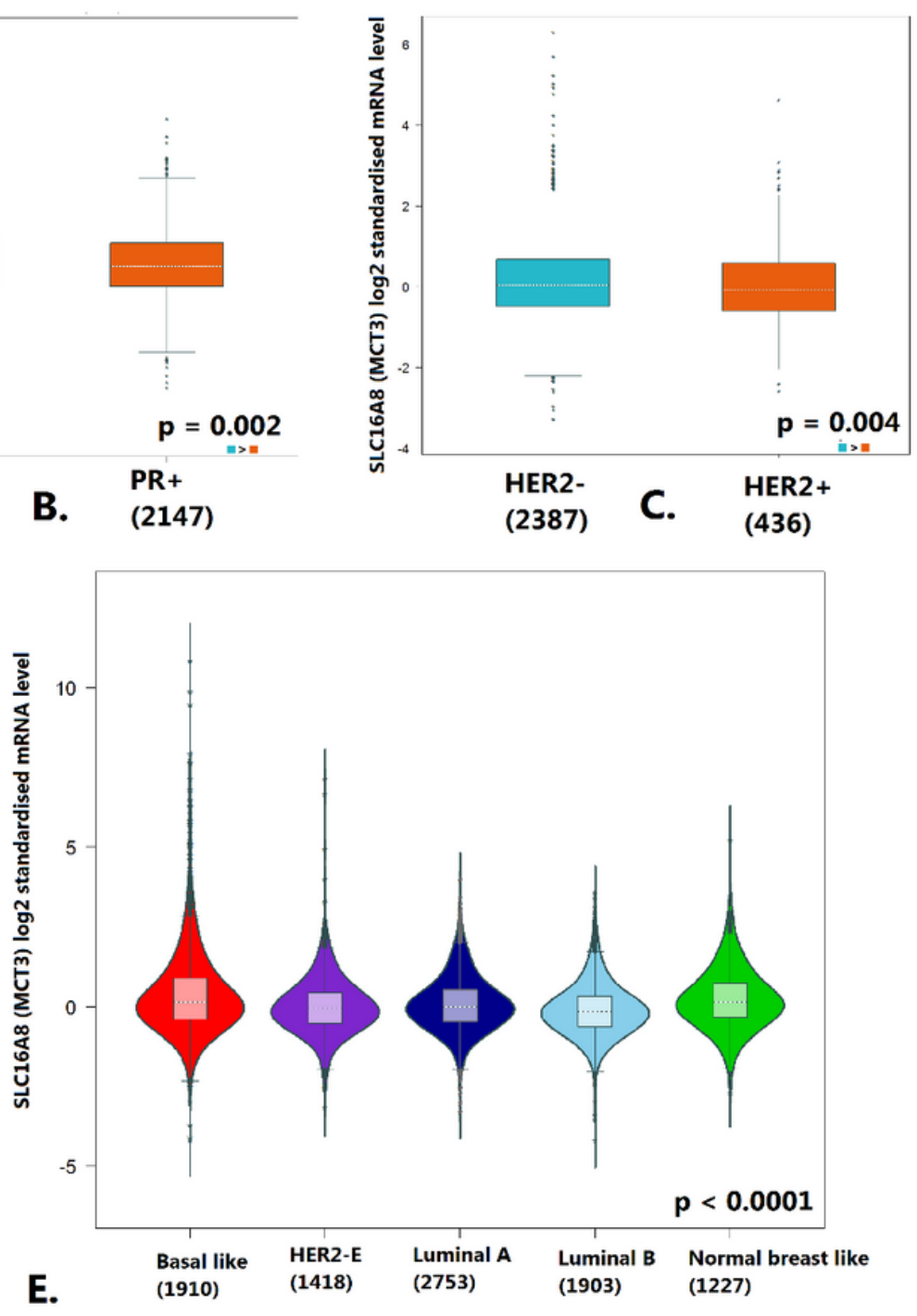

Figure 9

bc-GenExMiner data analysis of the mRNA level of MCT3 (SLC16A8) gene in different Receptor, age and subtype statuses in DNA microarray data. Box and whisker plot of SLC16A8 (MCT3) expression according to ER (A), PR (B) and HER2 (C) by IHC. Beeswarm plot of MCT3 gene in different age (D). Violin plot of MCT3 gene in different intrinsic molecular subtype according to PAM50 subtypes in DNA microarray data $(E)$. 

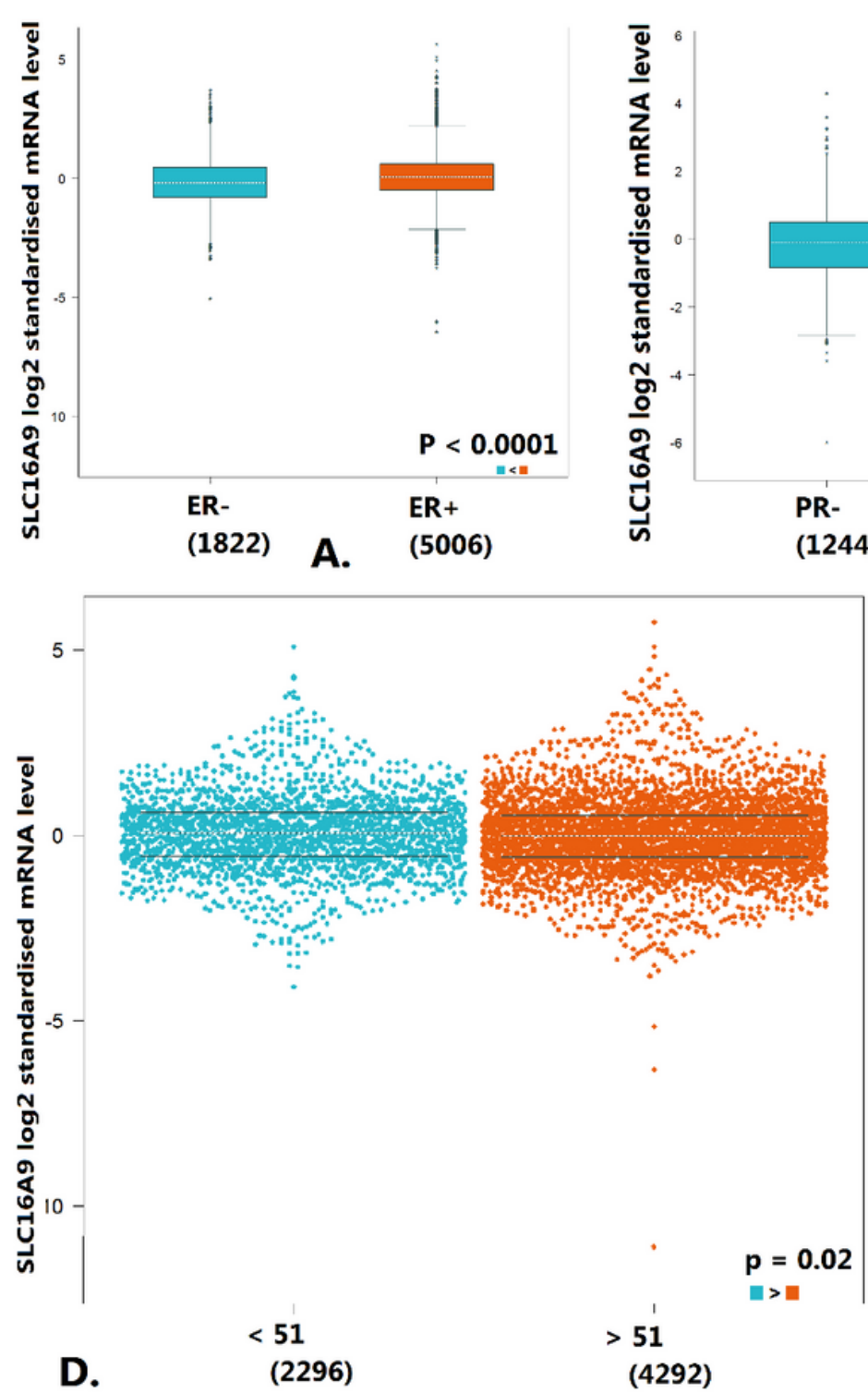
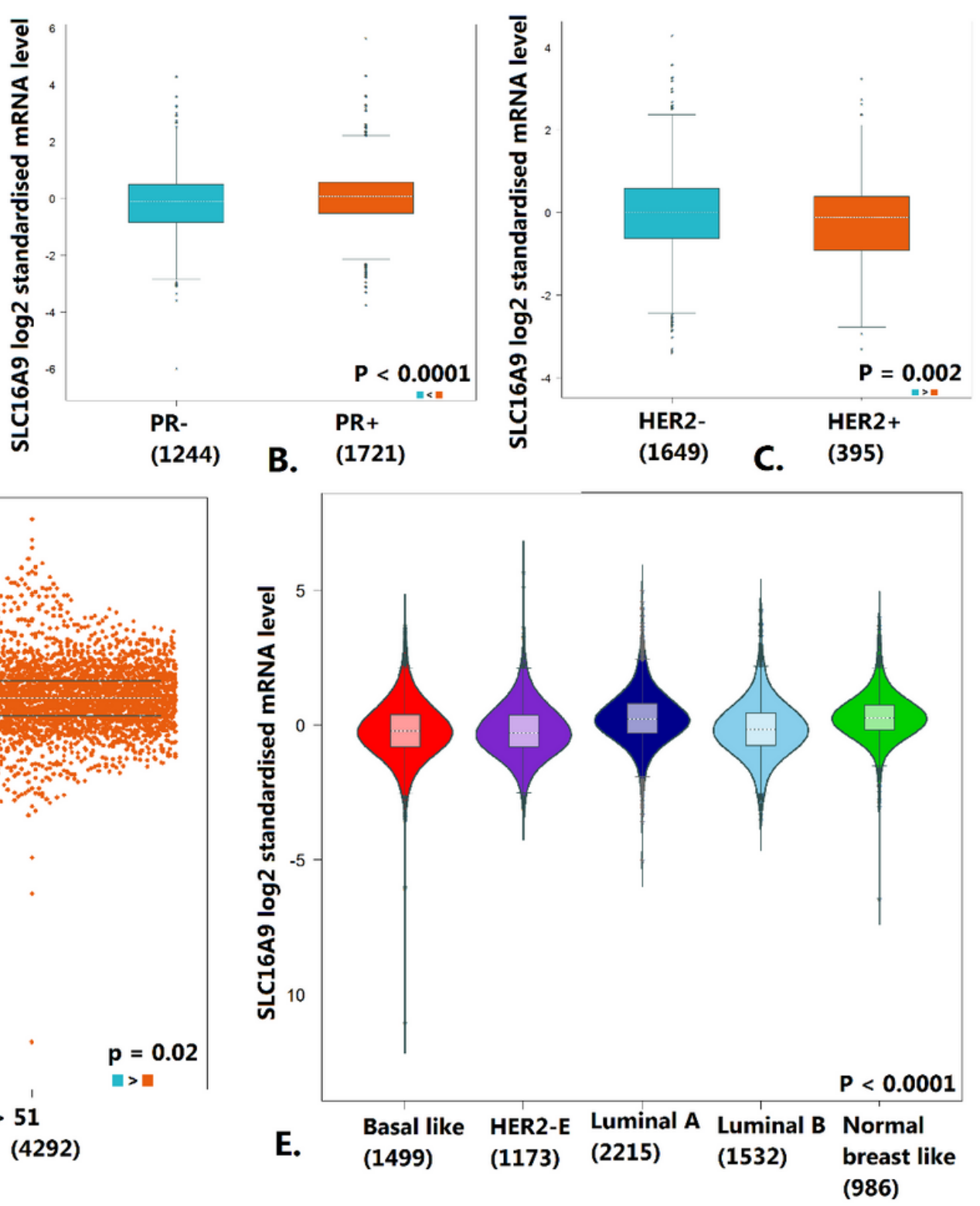

Figure 10

bc-GenExMiner data analysis of the mRNA level of MCT9 (SLC16A9) gene in different Receptor, age and subtype statuses in DNA microarray data. Box and whisker plot of MCT9 (SLC16A9) expression according to ER (A), PR (B) and HER2 (C) by IHC. Beeswarm plot of MCT9 gene in different age (D). Violin plot of MCT9 gene in different intrinsic molecular subtype according to PAM50 subtypes in DNA microarray data $(E)$. 
SLC16A9 (227506_at)

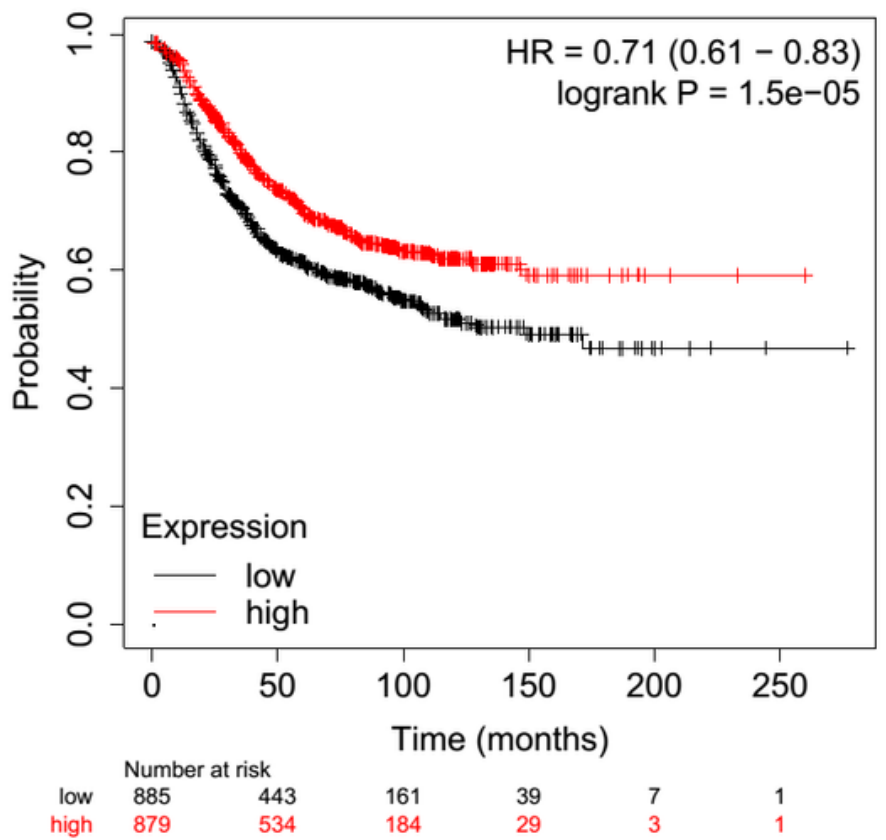

A.

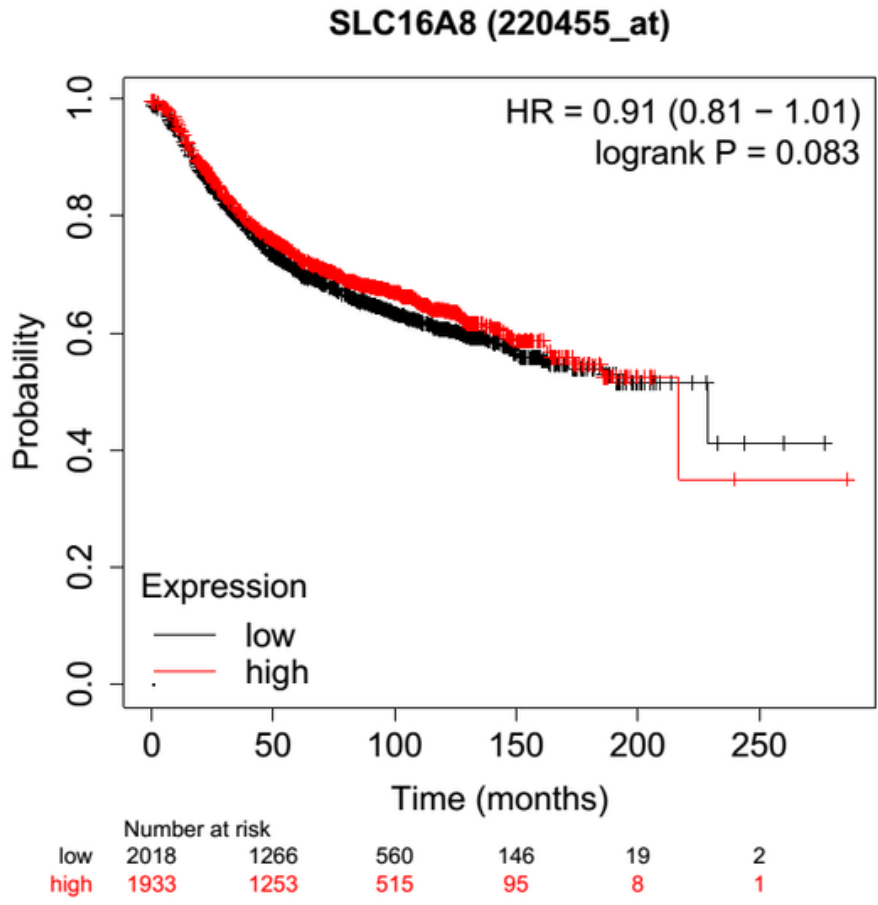

B.

SLC16A2 (204462_s_at)

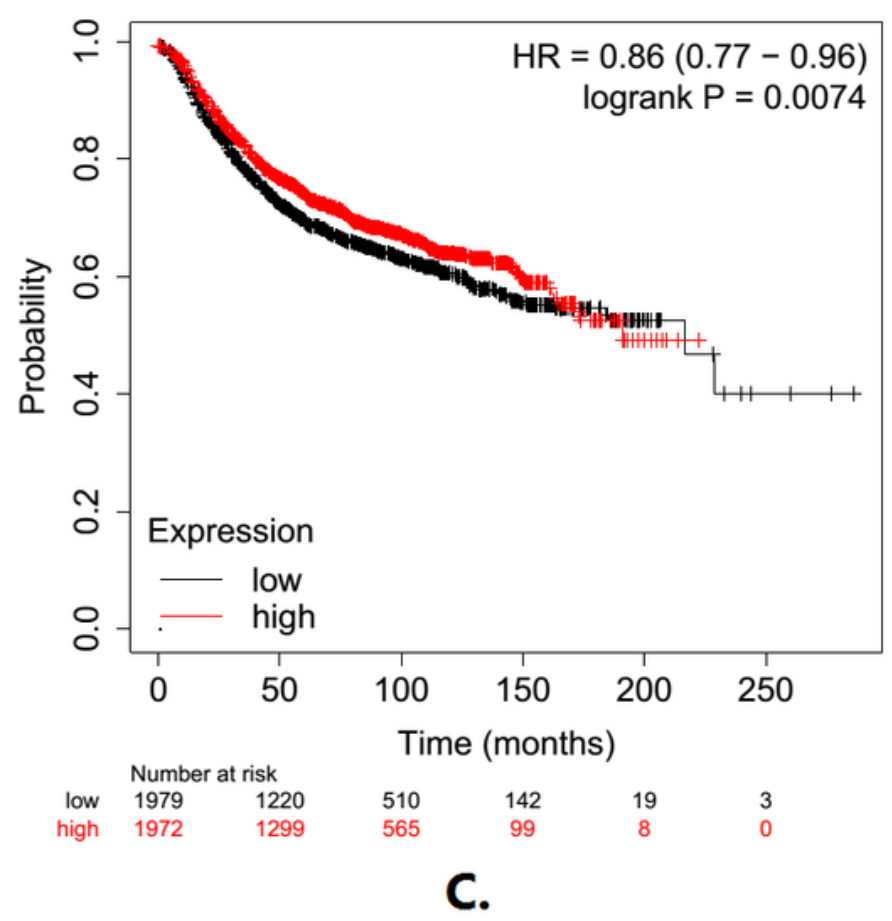

\section{Figure 11}

A) Kaplan-Meier (https://kmplot.com/analysis/) survival curve showing the prognostic value of SLC16A9 (MCT9) in predicting BC using the Pan-cancer analysis. Low expression of mRNA indicated poor overall survival. B) Low expression of SLC 16A8 (MCT3) showed no significant effect on survival (HRs; $95 \%$ confidence interval in parentheses). C) Low expression of SLC16A2 (MCT8) showed poor overall survival. 